\title{
Quick Sequential Organ Failure Assessment Score in Recognizing Infected Patients with Organ Dysfunction \& Prediction of Mortality: Cohort study
}

\author{
Jina Fadl ${ }^{1}$, Wisal Nabag ${ }^{2}$, and Mohamed A. A. El Sheikh ${ }^{1}$ \\ ${ }^{1}$ University of Khartoum Faculty of Medicine \\ ${ }^{2}$ Alzaiem Alazhari University
}

May 6, 2020

\begin{abstract}
Background: puerperal sepsis is a common cause of maternal mortality worldwide. Quick Sequential Organ Failure Assessment (q-SOFA) is a bedside tool which is composed of three components: respiratory rate, systolic blood pressure and level of consciousness, A score of [?] 2 indicates that the patient is having sepsis \& at risk of poor outcome. Objectives: To calculate the q-SOFA for postpartum patients admitted with infection and to correlate this with critical care unit admission \& patient outcome. Methods: An observational, prospective cohort hospital-based study. It was conducted in Omdurman Maternity Hospital from October 2018-to March 2019. The study included 59 postpartum patients who were diagnosed with postpartum infection; their q-SOFA score was calculated on admission and then on daily basis, to detect their in-hospital mortality and morbidity. The data was analyzed using SPSS, using Pearson Chi-square which was significant at $\mathrm{P}$ value of 0.05 . Results: Fifty-nine participants were involved, mean age was 28years. Those who delivered by cesarean section was 54.3\%, 33(55.9\%) developed surgical site infection. Five patients (8.5\%) died and $54(91.5 \%)$ discharged. $17(28.8 \%)$ were admitted to critical care unit. q-SOFA score was calculated \& correlated to critical care unit admission \& fate of the patient using Pearson Chi-square which was found to be significant 0.01 and 0.001 , respectively ( $\mathrm{P}$ value of 0.05 ). Conclusion: q-SOFA is a useful tool in detecting infected patients at risk of poor outcome and death. If the score [?]2 patients need to be, admitted to critical care unit
\end{abstract}

\section{Hosted file}

final manuscript edited for bjog.doc available at https://authorea.com/users/317861/articles/ 447942-quick-sequential-organ-failure-assessment-score-in-recognizing-infected-patientswith-organ-dysfunction-prediction-of-mortality-cohort-study

\section{Hosted file}

Figures.docx available at https : //authorea.com/users/317861/articles/447942-quick-sequentialorgan-failure-assessment-score-in-recognizing-infected-patients-with-organ-dysfunctionprediction-of-mortality-cohort-study 